\title{
A unique strain of community-acquired Clostridium difficile in severe complicated infection and death of a young adult
}

\author{
Orville D Heslop ${ }^{1 *}$, Karen Roye-Green ${ }^{1+},{\text { Kathleen } \text { Coard }^{2+} \text { and Michael R Mulvey }}^{3+}$
}

\begin{abstract}
Background: Clostridium difficile is the major cause of nosocomial antibiotic-associated diarrhoea with the potential risk of progressing to severe clinical outcomes including death. It is not unusual for Clostridium difficile infection to progress to complications of toxic megacolon, bowel perforation and even Gram-negative sepsis following pathological changes in the intestinal mucosa. These complications are however less commonly seen in community-acquired Clostridium difficile infection than in hospital-acquired Clostridium difficile infection. To the best of our knowledge, this was the first case of community-acquired Clostridium difficile infection of its type seen in Jamaica.

Case presentation: We report a case of a 22-year-old female university student who was admitted to the University Hospital of the West Indies, Jamaica with a presumptive diagnosis of pseudomembranous colitis PMC. She presented with a 5-day history of diarrhoea following clindamycin treatment for coverage of a tooth extraction due to a dental abscess. Her clinical condition deteriorated and progressed from diarrhoea to toxic megacolon, bowel perforation and Gram-negative sepsis. Clostridium difficile NAP12/ribotype 087 was isolated from her stool while blood cultures grew Klebsiella pneumoniae. Despite initial treatment intervention with empiric therapy of metronidazole and antibiotic clearance of Klebsiella pneumoniae from the blood, the patient died within 10 days of hospital admission.

Conclusions: We believe that clindamycin used for coverage of a dental abscess was an independent risk factor that initiated the disruption of the bowel micro-flora, resulting in overgrowth of Clostridium difficile NAP12/ribotype 087. This uncommon strain, which is the same ribotype (087) as ATCC 43255, was apparently responsible for the increased severity of the infection and death following toxic megacolon, bowel perforation and pseudomembranous colitis involving the entire large bowel. K. pneumoniae sepsis, resolved by antibiotic therapy was secondary to Clostridium difficile infection. The case registers community-acquired Clostridium difficile infection as producing serious complications similar to hospital-acquired Clostridium difficile infection and should be treated with the requisite importance.
\end{abstract}

Keywords: Clostridium difficile, Klebsiella pneumoniae, Community-Acquired Infection, Diarrhoea, Clindamycin, Pseudomembranous Colitis, Toxic Megacolon

\footnotetext{
* Correspondence: orville.heslop@uwimona.edu.jm

'Equal contributors

'Department of Microbiology, University of the West Indies, Kingston, Jamaica

Full list of author information is available at the end of the article
} 


\section{Background}

Clostridium difficile ( $C$. difficile) is the major cause of nosocomial antibiotic-associated diarrhoea [1,2], while secondary Gram-negative shock in community-acquired Clostridium difficile infection (CA-CDI) may occur following bowel perforation in hospitalised patients [3]. CA-CDI is defined as symptoms that occur in the community or within 48 hours of admission to a hospital, provided symptoms from onset were $>12$ weeks after the last discharge from a hospital [3]. CA-CDI occurs less frequently than hospital-acquired $C$. difficile infection (HA-CDI). It is usually less severe and presents more frequently among females with a median age of 50 years compared to 72 years with HA-CDI [3]. The most common risk factors associated with CDI are broad-spectrum antibiotics including third generation cephalosporins, clindamycin, penicillins and, more recently, fluoroquinolones $[2,4]$. However, virtually all antibiotics are potential risk factors for CDI [5]. We highlight the unusual strain $C$. difficile ribotype 087 and pulsed-field gel electrophoresis (PFGE) type 0515 associated with severe complicated CDI, which was being seen for the first time in Jamaica. Klebsiella pneumoniae (K. pneumonia) sepsis, a subsequent clinical outcome, was diagnosed from positive blood cultures after a 5day history of apparent clindamycin-induced diarrhoea in CA-CDI.

\section{Case presentation}

A 22-year-old female presented to the University Hospital of the West Indies, Jamaica for further investigation and management following transfer from a local Government hospital where she presented with a 5-day history of diarrhoea and fever. The diarrhoea commenced 5 days after starting clindamycin therapy for a recent tooth extraction due to a dental abscess. Despite discontinuation of clindamycin therapy and the introduction of chloramphenicol and metronidazole empiric therapy, the diarrhoea and fever continued.

Physical examination of the patient revealed a febrile female in severe cardiopulmonary distress with tachycardia, HR beats/150 min, and blood pressure 150/ $100 \mathrm{~mm} / \mathrm{Hg}$. Laboratory investigations showed haemoglobin of $10.4 \mathrm{gm} / \mathrm{dl}$, white cell count of $2.1 \times 10^{9} /$ litre, and platelet count of $182 \times 10^{9} /$ litre. Diarrhoea persisted and progressed to toxic megacolon and bowel perforation. Blood cultures (brain heart infusion and thioglycollate broths) collected on admission grew K. pneumoniae from all four bottles after 24 hours incubation at $37^{\circ} \mathrm{C}$. Diarrhoeal stool specimen sent the day after admission was positive for C. difficile toxin A/B (ELISA; Alexon Inc. 1190 Borregas Ave., Sunnyvale, CA. 94089-1302) and the corresponding organism isolated on selective culture medium, cycloserine, cefoxitin, fructose agar (CCFA).
In the interim period of empiric therapy, susceptibility testing on K. pneumoniae by the Kirby Bauer disc diffusion method showed susceptibilities to ceftriaxone, cotrimoxazole, ceporin, amikacin, gentamicin, ceftazidine, and augmentin, as well as resistance to chloramphenical, piperacillin and ampicillin. The patient continued therapy on intravenous metronidazole and with the introduction of ceftriaxone and gentamycin she became afebrile with subsequent blood cultures becoming sterile. Hypotension, pulmonary oedema, leucopenia, and thrombocytopenia persisted despite appropriate therapy and intensive care management. The patient died 10 days after hospital admission and an autopsy was performed. The most significant finding of the autopsy was multiple discrete plaques of yellowish exudate on the mucosal surface of the entire large bowel typical of pseudomembranous colitis (PMC), which was florid. Another noteworthy pathologic finding was that of markedly overweight lungs with features in keeping with adult respiratory distress syndrome.

Polymerase chain reaction (PCR) was used to confirm the presence of $C$. difficile triphosphate isomerase (tpi), toxin genes $t c d A$ and $t c d B$, the lack of binary toxin $c d t B$ gene, and no deletion in $t c d C$ gene [6]. PCR ribotyping on the isolate revealed a ribotype of 087 and the pulsedfield gel electrophoresis (PFGE) macrorestriction pattern identified a fingerprint type 0515 , not previously seen using this method, and when compared to a national collection of over 700 unique fingerprint types from more than 7,100 CDI isolates (Figure 1). However, the fingerprint pattern was closely related to the North American Pulsotype (NAP) NAP12 strain with only a one band difference (Figure 1). The minimal inhibitory concentrations (MIC) determined by Etest were as follows: susceptible to metronidazole $0.094 \mathrm{ug} / \mathrm{ml}$; vancomycin $1 \mathrm{ug} / \mathrm{ml}$; moxifloxacin $1 \mathrm{ug} / \mathrm{ml}$; rifampicin $<0.002 \mathrm{ug} / \mathrm{ml}$; tigecycline $0.125 \mathrm{ug} / \mathrm{ml}$; and resistant to clindamycin $256 \mathrm{ug} / \mathrm{ml}$. K. pneumoniae was isolated from 2 sets of blood cultures following overnight incubation at $37^{\circ} \mathrm{C}$.

The severe clinical outcomes seen in the present case were not unusual though more commonly seen in HACDI [3]. In addition to these clinical presentations, associated hypotension and admission to the intensive care unit classified this patient as a severe complicated case of CDI [7]. In a large study covering the period 19912005 in Olmsted County, Minnesota, it was interesting to note that only $4 \%$ of CA-CDI had progressed to severe complicated CDI [8]. It was further noted that such cases are usually associated with a significantly older age group with a median age of 80 years [8]. The manifested clinical involvements along with a significant age difference are important features to consider in CA-CDI and should serve to alert clinicians that there is always a potential risk of young adults progressing to severe complicated CDI. The source of $K$. pneumoniae sepsis in the 


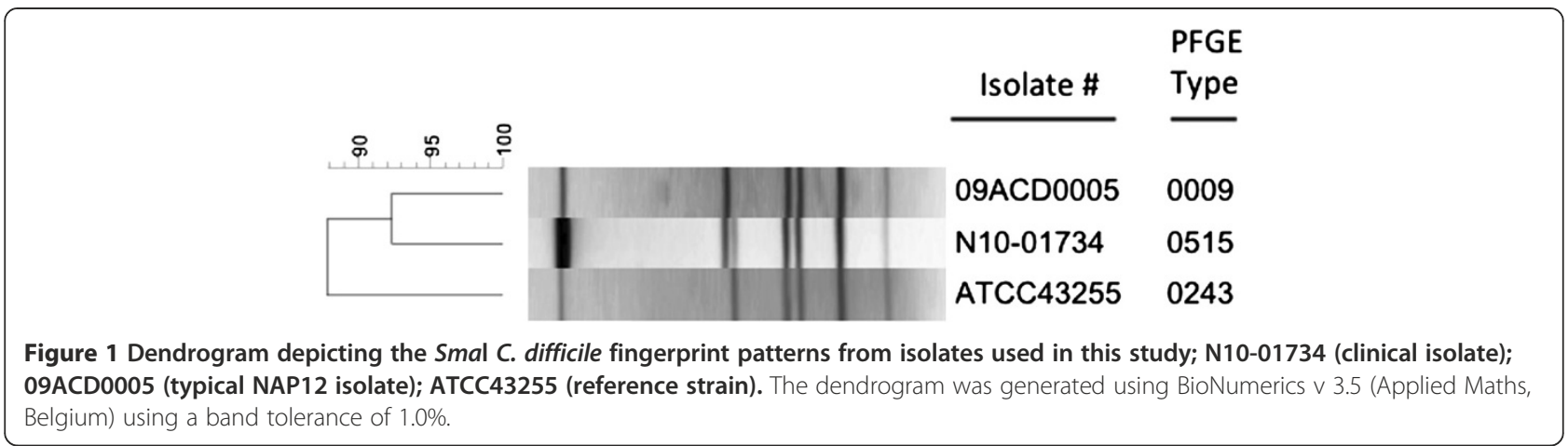

patient was presumably the gastrointestinal tract, as there were no symptoms or signs to suggest other systems involvement. Notwithstanding treatment with metronidazole, the patient was unresponsive and progressed to toxic megacolon and bowel perforation. These were probably due to the failure to administer appropriate and adequate clinical and surgical interventions.

Oral metronidazole remained the preferred first line drug for treatment while vancomycin is reserved for severely ill patients and recurrence of $C$. difficile colitis [9]. Interestingly, these interventions including the use of adjunctive intracolonic vancomycin therapy and total colectomy, as recommended options, were not followed in the management of the present case. It is important to note that PMC was confirmed by autopsy. The failure to apply the optimal required clinical and surgical interventions during the patient's hospitalisation were probably due to the rapid progression of these clinical outcomes.

With the exception of toxins A and B produced by this isolate, there was no deletion observed in the negative regulator $t c d C$ gene suggesting normal toxin expression. However, ATCC 43255, which also has a wild type $t c d C$, has shown increased toxin expression [10]. Importantly, ATCC 43255 has the same ribotype (087) as the clinical isolate and only a single band difference in the DNA fingerprints was observed between the two isolates (Figure 1). Based on the similarity of ribotypes and fingerprint patterns between the two isolates, one could speculate that the rapid progression to PMC in the patient may be due to increased toxin expression. Ribotype 087 is the predominant strain in Hungary but is uncommon internationally [11].

The patient had no history of hospitalisation 12 months prior to infection and no health care-associated risk factors to CDI were noted. On the contrary, this young adult female was actively pursuing a university education, which was disrupted by CA-CDI [3]. The progression to toxic megacolon in the patient was not a predicted clinical outcome even after hospitalisation. The presence of a perforated colon was a clear indication for surgical intervention, especially if there were unresponsiveness to other treatments and if clinical improvement was not noted within 2 to 3 days of patient management [12].

\section{Conclusions}

To the best of our knowledge, this was the first case of CA-CDI of its type seen in Jamaica, and was fraught with many challenges including diagnosis and clinical management. The clinical manifestations of CA-CDI rapidly progressed to serious complications but were not given the appropriate and timely treatment interventions. We believe that clindamycin used for coverage of a dental abscess was an independent risk factor that initiated the disruption of the bowel micro-flora resulting in overgrowth of NAP12/ribotype 087. This was apparently responsible for the increased severity of CDI seen in the patient. The progression to death was the result of complications from florid PMC while K. pneumoniae sepsis was secondary to bowel perforation initiated by pathological changes in the intestinal mucosa.

These findings underscore two important points that clinicians should note: [1] the need to use clindamycin more discriminately in spite of its excellent coverage as a broad-spectrum antibiotic, and [2] to be more alert in recognising the potential risk of CA-CDI progressing to severe complicated CDI in young adults. Additionally, clinicians and other healthcare providers should be prudent to employ appropriate patient management to reduce the morbidity and mortality rate among hospitalised C. difficile infected individuals.

\section{Consent}

Written informed consent was obtained from the parents of the patient for publication of this Case report and any accompanying images. A copy of the written consent is available for review from the Series Editor of this journal.

The investigation of $C$. difficile infection whether acquired in a hospital or in the community is an ongoing research study, approved by the UHWI Ethics Committee. 
The present case study would be included even though this particular case occurred sometime before we received ethical approval. Please see attached letter from the UHWI Ethics Committee.

\section{Competing interests}

All authors declare that they have no competing interests.

\section{Authors' contributions}

All authors read and approved the final manuscript. OH wrote the manuscript and conducted the initial laboratory diagnosis of the present case. KRG wrote the case report along with KC who wrote the pathological findings. MM conducted the genotyping of the clinical isolate, and contributed to the molecular analysis and to writing the manuscript.

\section{Acknowledgements}

We would like to thank the following employees of the National Microbiology Laboratory in Winnipeg, Canada for their efforts towards this manuscript. Tim Du (MSC) for PCR and typing analysis, and Romeo Hizon RT (BSC) for assistance in antimicrobial susceptibility testing of the C. difficile isolate.

\section{Author details}

'Department of Microbiology, University of the West Indies, Kingston, Jamaica. ${ }^{2}$ Department of Pathology, University of the West Indies, Kingston, Jamaica. ${ }^{3}$ National Microbiology Laboratory, 1015 Arlington Street, Winnipeg MB R3E 3R2, Canada.

Received: 11 January 2013 Accepted: 21 June 2013

Published: 1 July 2013

\section{References}

1. Apisarnthanarak A, Khoury H, Reinus WR, Crippin JS, Mundy LM: Severe Clostridium difficile colitis: the role of intracolonic vancomycin? Am J Med 2002, 112:329-329.

2. Aslam S, Musher D: An update diagnosis, treatment, and prevention of Clostridium difficile associated disease. Gastroenterol Clin Am 2006, 35:315-335.

3. Khanna S, Pardi DS, Aronson SL, Kammer PP, Orenstein R, St Sauver JL, Harmsen WS, Zinsmeister AR: The epidemiology of community acquired Clostridium difficile infection: A population based study. Am J Gastroenterol 2012, 107(1):89-95. http://www.endonurse.com/.

4. Bartlett JG, Chang TW, Gurwith M, Gorbach SL, Onderdonk AB: Antibioticassociated pseudomembranous colitis due to toxin-producing clostridia. N Engl J Med 1978, 298:531-534.

5. Owens RC, Donskey CJ, Gaynes RP, Loo VG, Muto CA: Antimicrobial Associated Risk Factors for Clostridium difficile Infection. Clin Infect Dis 2008, 46(Suppl 1):S19.

6. Mulvey MR, Boyd DA, Gravel D, Hutchinson J, Kelly S, Mcgeer A, Moore D, Simor A, Suh KN, Taylor G, Weese S, Miller M: Hyper-virulent Clostridium difficile strains in hospitalised patients, Canada. Emerg Infect Dis 2010, 16(4):678-681.

7. Cohen SH, Gerding DN, Johnson S, Kelly CP, Loo VG, McDonald LC, Pepin J, Wilcox MH: Clinical practice guidelines for Clostridium difficile infection in adults: 2010 update by the society for healthcare epidemiology of America (SHEA) and the infectious diseases society of America (IDSA). Infect Control Hosp Epidemiol 2010, 31:431-455.

8. Khanna S, Pardi DS, Aronson SL, Kammer PP, Baddour LM: Outcomes in community-acquired Clostridium difficile infection. Aliment Pharmacol Ther 2012, 35(5):613-618.

9. Koss K, Clark MA, Sanders DS, Morton D, Keighley MB, Goh J: The outcome of surgery in fulminant Clostridium difficile colitis. Colorectal Dis 2006, 8(2):149-154.

10. Murray R, Boyd D, Levett PN, Mulvey MR, Alfa MJ: Truncation in the $t c d C$ region of the Clostridium difficile PatLoc of clinical isolates does not predict increased biological activity of Toxin B or Toxin A. BMC Infect Dis 2009, 9:103.

11. Urbán E, Brazier JS, Sóki J, Nagy E, Duerden BI: PCR ribotyping of clinically important Clostridium difficile strains from Hungary. J Med Microbiol 2001, 50:1082-1086.

12. Sayedy L, Kothari D, Richards RJ: Toxicmegacolon associated Clostridium difficile colitis. World J Gastrointest Endosc 2010, 2(8):293-297.

doi:10.1186/1471-2334-13-299

Cite this article as: Heslop et al:: A unique strain of community-acquired Clostridium difficile in severe complicated infection and death of a young adult. BMC Infectious Diseases 2013 13:299.

\section{Submit your next manuscript to BioMed Central and take full advantage of:}

- Convenient online submission

- Thorough peer review

- No space constraints or color figure charges

- Immediate publication on acceptance

- Inclusion in PubMed, CAS, Scopus and Google Scholar

- Research which is freely available for redistribution

Submit your manuscript at www.biomedcentral.com/submit 